\title{
Achromatopsia in the aura of migraine
}

\author{
Mark C Lawden, Peter G Cleland
}

\begin{abstract}
A 49 year old woman reported an attack of transient neurological dysfunction associated with unilateral headache. A prominent feature of the aura was a period of complete achromatopsia, so that the visual scene was experienced in monochrome. The episode developed to include features of prosopagnosia and spatial agnosia before resolving completely. Other episodes of transient neurological dysfunction followed at regular intervals until prophylactic antimigrainous therapy was initiated. Four vessel cerebral angiography and MRI of the brain were normal. Possible causes of this unusual migrainous aura are discussed with reference to current concepts of cerebral localisation.
\end{abstract}

(F Neurol Neurosurg Psychiatry 1993;56:708-709)

Migraine is well known to produce a wide variety of visual disturbances. These can range from teichopsia and visual scotomas to more complex metamorphopsia and visual hallucinations. ${ }^{1-3}$ However, distortions of colour vision seem relatively rare accompaniments of migraine and complete achromatopsia has not been described before.

\section{Case report}

The patient was a 49 year old right handed woman in good general health. While buying wool in a shop she made a mistake in selection, picking up dark blue wool rather than the brown colour that she wanted. The shop assistant pointed out her mistake and she took it back to the shelves to replace it. Then, over a period of a few seconds, colour faded away completely so that the shop and its contents appeared in monochrome. She developed a right sided frontoparietal headache and left the shop for some fresh air. Over the next few minutes colour returned to the scene, but she became completely lost. Although she was only a few blocks from her house she had no idea in which direction it lay. She was also unable to recognise a close friend who was accompanying her. Her friend took her home where she slept for several hours, awakening fully recovered.
One month before this episode the patient had experienced a transient neurological disturbance while working at her hospital telephone exchange. On this occasion her console suddenly looked unfamiliar and she "didn't recognise it". She was not able to recognise her workmate, though she could understand and reply to speech. Colour vision remained subjectively normal. She then developed a severe pounding right sided headache, was admitted to a bed on a nearby ward and slept for several hours. On awakening she was fully recovered.

For about a year after these two episodes she experienced further attacks of neurological dysfunction at intervals of two to three weeks. These were stereotyped, beginning with a right frontoparietal headache and followed by clumsiness of the left arm. During the attacks she was unable to perform any fine movement with the left hand, or to drink from a cup without spilling the contents. There was no subjective weakness of the hand though attacks were sometimes associated with tingling paraesthesia and numbness. She had also noticed a tendency to bump into objects on the left side during attacks, but denied any visual disturbance. The attacks lasted from two to three hours before resolving completely.

The only relevant feature of her history was that in 1981 she suffered a brief episode of weakness of the left arm associated with tingling paraesthesia, which resolved completely after a few hours. There was no previous history of migraine headaches. Two of her three siblings died suddenly from subarachnoid haemorrhages in their forties, one of whom had previously complained of migraine. She smoked 15 cigarettes a day, but there were no other risk factors for vascular disease.

On examination there were no abnormal neurological signs; in particular, her colour vision was normal when tested with Ishihara plates. The general examination was likewise normal: there were no cardiac murmurs or arterial bruits, and the blood pressure was $140 / 80$. A four vessel cerebral angiogram was normal. An MRI scan of the brain was also normal.

In the absence of any evidence of structural pathology it was concluded that these attacks were migrainous in nature and she was treated 
prophylactically with Pizotifen $1.5 \mathrm{mg}$ at night. Since beginning this medication the patient has reported no further migrainous symptoms.

\section{Discussion}

We believe that this woman's attacks of neurological dysfunction associated with unilateral headache satisfy the diagnostic criteria of the International Headache Society for migraine with aura. ${ }^{4}$ Specifically, on several occasions she has experienced one or more fully reversible focal aura symptoms developing gradually over more than four minutes, lasting less than 60 minutes, and followed by headache. The alternative diagnosis of transient ischaemic attacks is, we believe, made implausible by the association of unilateral headache with the auras, and by the normal angiogram. Although visual disturbances are common in migraine, specific disturbances of colour vision have rarely been described. Hoeflmayer ${ }^{5}$ described a 57 year old woman who, during recovery from an exceptionally prolonged and severe migraine attack lasting 10 days, suffered from a variety of metamorphopsia and perceived colours as darker than normal. Klee and Willanger, ${ }^{1}$ in an extensive survey of the early literature on migrainous disturbances of visual perception, refer only to the case of Hoeflmayer as exhibiting apparent changes of colour perception. In addition, two of their own patients reported that "chromatic colours gradually paled and became greyish". Hachinski et al $^{2}$ analysed the visual symptoms experienced by 100 migrainous children, one of whom stated that "the colours of the objects she looked at changed, though she was unable to say just how".

Current concepts of the pathogenesis of the classical migrainous aura centre upon spreading depression, ${ }^{6}$ and oligaemia. Studies of changes in regional cerebral blood flow (rCBF) have demonstrated reduced occipital perfusion during the aura, which gradually spreads anteriorly in the affected hemisphere. ${ }^{7}$ Spreading depression is an experimental phenomenon first described by Leao $^{8}$ in which a wave of suppressed electrical activity associated with profound changes in extracellular ion concentrations spreads across the cortical surface at a similar rate to the oligaemia mentioned above (about $2 \mathrm{~mm} / \mathrm{min}$ ). It has yet to be shown that spreading depression can occur sponta- neously in the human cortex and whether the oligaemia is a primary or a secondary event.

Evidence has accumulated that the human colour centres are located on the medial surfaces of the cerebral hemispheres in the fusiform and/or the lingual gyri, close to the occipito-temporal junction. Small bilateral cerebral lesions in this region can produce cerebral achromatopsia. ${ }^{910}$ Achromatopsia is often associated with both prosopagnosia and loss of spatial orientation ${ }^{11}$ both of which were experienced by our patient. Prosopagnosia occurs in lesions of the fusiform gyri, which may or may not be bilateral. ${ }^{112}$ Spatial disorientation is found most often in parietal lesions.

We suggest that our patient's migrainous disturbance originated in the visual area devoted to colour processing, spreading anteriorly and superiorly into those parts of the temporal and parietal cortices concerned with face recognition and spatial orientation respectively. As her transient achromatopsia occupied the whole visual field, the disturbance must have been bilateral from its beginning. As no visual field defect was experienced at any stage it seems likely that the primary visual cortex and underlying white matter optic radiations were spared throughout. Her single earlier episode of object agnosia and prosopagnosia with sparing of colour vision probably arose from a slightly more anterior area, whereas her subsequent attacks of left arm apraxia presumably originated in the right superior lateral parietal lobe.

1 Klee A, Willanger $R$. Disturbances of visual perception in migraine. Acta Neurol Scand 1966;42:400-14.

2 Hachinski VC, Porchawka J, Steele JC Visual symptoms in the migraine syndrome. Neurology 1973;23:570-9.

3 Hupp SL, Kline LB, Corbett JJ. Visual disturbances of migraine. Surv Ophthalmol 1989;33:221-36.

4 International Headache Society Classification and diagnostic criteria for headache disorders, cranial neuralgias and facial pain. Cephalalgia 1988;(Suppl)7:1-96.

5 Hoeflmayer L. Eine merkwurdige Komplikation eines Migraneanfalles. Neurol Zentralblat 1903;3:102-9.

6 Lauritzen M. Cortical spreading depression as a putative migraine mechanism. Trends Neurosci 1987;10:8-13.

7 Olesen J, Larsen B, Lauritzen $M$. Focal hyperemia followed by spreading oligemia and impaired activation of rCBF in classic migraine. Ann Neurol 1981;9:344-52.

8 Leao KAP. Spreading depression of activity in cerebral cortex. $\mathcal{F}$ Neurophysiol 1944;7:359-90.

9 Meadows JC. Disturbed perception of colours associated with localized cerebral lesions. Brain 1974;97:615-32.

10 Zeki S. A century of cerebral achromatopsia. Brain 1990;

11 Meadows JC. The anatomical basis of prosopagnosia. $f$ Neurol Neurosurg Psychiatry 1974;37:489-501.

12 Cohn RC, Neumann MA, Wood DH. Prosopagnosia: a clinicopathological study. Ann Neurol 1977;1:177-82. 